\title{
Factors affecting wound complications in head and neck surgery: A prospective study
}

\author{
Devendra A. Chaukar, \\ Anuja D. Deshmukh, \\ Tanveer Majeed ${ }^{l}$, \\ Pankaj Chaturvedi, \\ Prathamesh Pai, \\ Anil K. D'cruz
}

Department of Head \& Neck Oncology, Tata Memorial Centre, Parel, ${ }^{1}$ Joy Hospital, Mumbai, Maharashtra, India

\begin{abstract}
A B S T R A C T
Context: Head and neck surgeries are complex. Wound complications are associated with considerable morbidity and can result in delay in the adjuvant treatment. Identification of factors will help in formulating preventive guidelines. Aims: The aim of this study is to identify perioperative factors responsible for wound complications. Settings and Design: Prospective study of 186 head and neck patients. Subjects and Methods: Pre-operative, intraoperative and post-operative factors were recorded. Each patient was evaluated for minor and major wound complications twice daily during the hospital stay. Statistical Analysis: Chi-square test was used for univariate and log regression test was used for multivariate analysis. Results: The overall wound complication rate was $29 \%$ with $7 \%$ major and $22 \%$ minor complications. On univariate analysis, laryngeal and hypopharyngeal location, advanced T stage, poor oral hygiene, clean-contaminated surgery, low Karnofsky performance status (KPS), flap reconstruction, blood loss more than $1000 \mathrm{ml}$, perioperative blood transfusion, duration of surgery greater than $4.3 \mathrm{~h}$ and post-operative hemoglobin lesser than $11 \mathrm{~g} \%$, post-operative tracheostomy and resection of mandible were statistical significant factors. On multivariate analysis, post-operative tracheostomy, low KPS, post-operative serum albumin less than $3.7 \mathrm{~g} / \mathrm{dl}$ and duration of surgery greater than 4.3 h were significant factors. Conclusion: Apart from unavoidable factors, it is essential to take care of certain factors viz nutrition, haemoglobin, oral hygiene, asepsis and repeating antibiotics in prolonged surgery.
\end{abstract}

Key words: Head and neck cancers, risk factors, wound complications, wound infection

\section{INTRODUCTION}

Wound complications are a major problem in patients undergoing head and neck surgery. Presence of comorbidity, alcohol and tobacco abuse and malnutrition increase the risk of complications in this group of patients. Besides being a financial burden due to increase hospital stay, wound complications can delay adjuvant therapy and this has an impact on overall survival. ${ }^{[1]}$ Head and neck cancer surgery increases risk of wound infection due to contamination by bacterial flora of upper aerodigestive tract. It is imperative to understand and identify the risk factors responsible for wound complication in an effort to minimize incidence rate.

\begin{tabular}{|l|l|}
\hline \multicolumn{2}{|c|}{ Access this article online } \\
\hline Quick Response Code: & Website: \\
\hline & www.jmpo.org \\
\hline
\end{tabular}

\section{SUBJECTS AND METHODS}

We report, a prospective study conducted over a period of 6 months on 186 head and neck patients at a tertiary cancer center in India. Medical records were prospectively analyzed for incidence, risk factors associated with post-surgical wound complications over a period until the time of discharge. In all cases, surgery was performed with curative intent.

Surgical wounds were prepared by povidone iodine scrub (excluding thyroid cases) followed by denatured spirit and subsequently povidone iodine solution left over for $4 \mathrm{~min}$. All surgical wounds (except thyroid cases) were irrigated with dilute povidone iodine with normal saline (1:3) wash before closure.

All clean contaminated cases received pre-operative antibiotic prophylaxis $30 \mathrm{~min}$ prior to anesthesia and were continued for $72 \mathrm{~h}$ in the form of injectable antibiotics and subsequently changed to oral antibiotics for another period of 5 days. Clean cases received only one dose of antibiotic $30 \mathrm{~min}$ prior to the procedure. All clean contaminated cases received cefuroxime, amikacin and metronidazole and clean 
cases received cefuroxime and amikacin. The standard dose of antibiotic for pre-operative prophylaxis was cefuroxime $1.5 \mathrm{~g}$ IV followed by $750 \mathrm{mg}$ IV $12 \mathrm{~h}$, amikacin $750 \mathrm{mg}$ IV $24 \mathrm{~h}$ and metronidazole $500 \mathrm{mg}$ IV $8 \mathrm{~h}$.

Multiple variables recorded for each patient are listed in Table 1. Post-operative wound were evaluated twice daily until the end of the post-operative hospital stay. Complications were classified into major and minor complication as listed in Table 2.

Statistical analysis was carried out using the statistical package for the social sciences, version 14 for windows

\begin{tabular}{|c|c|c|}
\hline Pre-operative variables & Operative variables & $\begin{array}{l}\text { Post-operative } \\
\text { variables }\end{array}$ \\
\hline Age, sex, obesity & Type of surgery & Post-operative \\
\hline BMI & Mandibular resection & hemoglobin \\
\hline KPS & Neck dissection & Total leucocyte count \\
\hline ASA grade & Flap resection & Platelet count \\
\hline Co morbid condition & Operating surgeon & Serum albumin \\
\hline Tobacco addiction & Duration of surgery & Serum urea \\
\hline Alcohol consumption & Blood loss & Serum creatinine \\
\hline Nutritional status & Blood transfusion & \\
\hline Oral hygiene & Tracheostomy & \\
\hline \multicolumn{3}{|l|}{ Prior radiotherapy } \\
\hline \multicolumn{3}{|l|}{ Prior chemotherapy } \\
\hline \multicolumn{3}{|l|}{ Prior cancer surgery } \\
\hline \multicolumn{3}{|l|}{ Prior tracheotomy } \\
\hline \multicolumn{3}{|l|}{ T stage } \\
\hline \multicolumn{3}{|l|}{ N stage } \\
\hline \multicolumn{3}{|l|}{$\begin{array}{l}\text { Pre-operative } \\
\text { hemoglobin }\end{array}$} \\
\hline \multicolumn{3}{|l|}{ Total leucocyte count } \\
\hline \multicolumn{3}{|l|}{ Platelet count } \\
\hline \multicolumn{3}{|l|}{$\begin{array}{l}\text { Serum albumin, urea and } \\
\text { creatinine }\end{array}$} \\
\hline $\begin{array}{l}\text { Pre-operative } \\
\text { hospital stay }\end{array}$ & & \\
\hline
\end{tabular}

\section{Table 2: The major and minor complications as grouped according to the severity of complication}

Major complications 13 cases (7\%) Minor complications 41 cases (22\%)

Arterial hemorrhage (delayed)

Venous hemorrhage(delayed)

$>50 \%$ reconstruction flap necrosis

$>50 \%$ skin flap necrosis

Major orocutaneous fistula

Major pharyngocutaneous fistula
SPSS 14.0 software (SPSS inc.,Chicago, IL). Chi-square test was used for univariate analysis between different variables and occurrence of wound complications. The level of significance was set at $5 \%, P<0.05$. Univariate analysis was done for major and minor complications against variables recorded. Multivariate analysis was done using logistic regression analysis.

\section{RESULTS}

The study included 186 patients. There were 119 men and 67 women with age ranging from 16 to 85 with a median of 56 years. Oral cavity (113), larynx/hypo pharynx (21) and thyroid (21) were the most frequent sites of the primary tumor location followed by maxilla (08), Parotid (07) and others (16). Nearly, $22.6 \%$ were clean cases and $77.4 \%$ were clean contaminated cases.

A total of 147 patients had Karnofsky performance status (KPS) more than $80 \%$ and 39 patients had a score less than $80 \%$. The 149 cases were American Society of Anesthesiology (ASA) Grade I, 34 cases Grade II and 3 cases ASA III. The oral hygiene was poor in 153 cases and 31 patients were detected to be obese. 61 patients were moderate to severely malnourished and 117 were well-nourished.

The 35 cases were early stage (T1, T2) and 126 were advanced stage (T3, T4). All 28 patients underwent salvage surgery following radiotherapy or concurrent radiotherapy. All 12 patients had received neoadjuvant chemotherapy for locally advanced oropharyngeal cases. The mean pre-operative hospital stay was 9 days.

Pre-operative tracheostomy was done in five patients and post-operative tracheostomy was required in 54 cases. Neck Dissection along with primary tumor excision was done in $73.7 \%$, only neck dissection in $17.2 \%$ and intraoral wide excision of the primary tumor alone in $9.1 \%$ patients. Flap reconstruction was required in 81 cases.

The average blood loss per surgery was $485 \mathrm{ml}$ with the maximum of $2000 \mathrm{ml}$ and minimum of $50 \mathrm{ml}$. Blood transfusion was given in $30 \%$ of patients. The mean duration of surgery was $4.48 \mathrm{~h}$ with a maximum of $14 \mathrm{~h}$ and minimum of $1 \mathrm{~h}$. Post-operative low hemoglobin (less than $11 \mathrm{~g} \%$ ) observed in 54.8\% and low albumin (less than $3.7 \mathrm{~g} / \mathrm{dl}$ ) in $86.6 \%$ patients.

The overall post-operative wound complication rate was $29 \%$ (54 cases) with 7\% (13 cases) major complication and $22 \%$ (41 cases) minor complications. Table 3 shows the overall rate of wound complications. 
Post-operative wound swab was sent for culture in 18 cases, the most common organism was polymicrobial (Escherichia coli and Pseudomonas aeruginosa).

Univariate analysis showed multiple risk factors to have a statistically significant association with wound complications. They are listed in Table 4.

On multivariate analysis, we found the presence of post-operative tracheostomy, long duration of surgery, low post-operative albumin and low KPS as dependent factors responsible for wound complications as shown in Table 5.

\begin{tabular}{lc}
\hline Table 3: The overall rate of wound complications \\
\hline Wound complications & Overall rate \% \\
Reconstruction flap necrosis & 37.03 \\
Skin flap necrosis & 24.07 \\
Pharyngocutaneous fistula & 18.52 \\
Orocutaneous fistulae & 14.8 \\
Skin graft related infection & 3.7 \\
Hemorrhage & 3.7 \\
\hline
\end{tabular}

\begin{tabular}{|c|c|c|}
\hline Variables & $\begin{array}{l}\% \text { of wound } \\
\text { complications }\end{array}$ & $P$ value \\
\hline $\begin{array}{l}\text { Location of primary tumor-larynx/ } \\
\text { hypopharynx }\end{array}$ & 52 & $P=0.014$ \\
\hline Advanced T stage & 40 & $P=0.000$ \\
\hline Poor oral hygiene & 32 & $P=0.000$ \\
\hline $\begin{array}{l}\text { Type of surgery-clean } \\
\text { contaminated type }\end{array}$ & 36 & $P=0.000$ \\
\hline Low Karnofsky performance status & 49 & $P=0.005$ \\
\hline Flap reconstruction & 46 & $P=0.000$ \\
\hline $\begin{array}{l}\text { Neck dissection along with the primary } \\
\text { tumor surgery }\end{array}$ & 36 & $P=0.000$ \\
\hline Blood loss during the surgery $>1000 \mathrm{ml}$ & 63 & $P=0.000$ \\
\hline Blood transfusion & 50 & $P=0.000$ \\
\hline Duration of surgery $>4.3 \mathrm{~h}$ & 47 & $P=0.000$ \\
\hline Post-operative hemoglobin & 36 & $P=0.001$ \\
\hline Post-operative albumin level & 34 & $P=0.000$ \\
\hline $\begin{array}{l}\text { Post-operative presence of } \\
\text { tracheotomy or tracheostomy }\end{array}$ & 59 & $P=0.000$ \\
\hline Resection of mandible & 46 & $P=0.000$ \\
\hline
\end{tabular}

\begin{tabular}{lcc}
\hline \multicolumn{3}{l}{ Table 5: Multiple risk factors associated with } \\
wound complications on multivariate analysis \\
\hline Variables & P value & Odds ratio \\
Post-operative tracheotomy/tracheotomy & 0.001 & 0.265 \\
Duration of surgery & 0.029 & 0.397 \\
Post-operative albumin & 0.002 & 3.629 \\
Karnofsky performance status & 0.05 & 0.000 \\
\hline
\end{tabular}

\section{DISCUSSION}

Surgeries for head and neck tumors are at an increased risk of wound infection and complication. These are time consuming procedures and require complex reconstruction. Majority of patients are addicted to some form of tobacco and alcohol and also have a very poor dental hygiene. Most of these patients are nutritionally deficient due to pain and have altered deglutition due to tumor location.

In the current study, the overall rate of wound complications was $29 \%$. Majority were associated with wound infection and fistulae.

Surgical errors including faulty planning, tissue trauma, inadequate subcutaneous tunnel leading to vascular insufficiency and tension over the suture line may be the most important factors predisposing to infection in major head and neck procedures. In the present study, the surgical technique accepted was standard in all cases with the use of the same technique of drain insertion, hemostasis and wound closure. We did not find any statistical significance among different operating surgeons.

We found the presence of post-operative tracheostomy, longer duration of surgery, low post-operative albumin and low KPS as independent factors on multivariate analysis.

The presence of post-operative tracheostomy was found as a significant factor as other studies. The colonization of the wound with tracheal secretion leads to the wound infection. Presence of saprophytic flora of skin and respiratory tract and presence of foreign body favors the infection to persist. ${ }^{[2-7]}$

Prolonged duration of surgery was more than $4.3 \mathrm{~h}$ and found to be significant. The mechanism has not been elucidated, but this may be because of the longer time of wound exposure to the environment, dampening of the surgical drapes with blood, complexity of a procedure associated with the longer duration with more blood loss. Antibacterial surgical scrubs may lose their effectiveness after some undisclosed time. Depending on the half-life of the given prophylactic antibiotic, it may be necessary to repeat the dose of the drug during prolonged surgery. ${ }^{[7-11]}$

We found a significant association between wound complications and low post-operative albumin. Albumin fall is associated with a fall in the important serum proteins of the immune system, which are essential for resistance to infection and to many toxic substances. Adequate nutrition with sufficient high biological value protein should be 
provided to these patients. One study has suggested that the enriched enteral formula with arginine and fiber enhanced supplements in early post-operative period improve immunological status, speed up recovery from immunosuppression and improves wound complications in the post-operative head and neck cancer patients. ${ }^{[12]}$

Patients of low KPS lesser than $80 \%$ did worse as compared with the patients greater than $80 \%$. This may be indirect marker of the underlying disease status, nutritional status and general condition of patient.

On univariate analysis, larynx and hypopharynx were the primary sites associated with the high risk of wound complication. ${ }^{[2-4]}$ This is probably because of the prolonged duration of surgery, complexity of the surgical procedure associated with contamination of surgical wound due to salivary and tracheal secretions.

Advanced $\mathrm{T}$ stage, ${ }^{[2,6,13,14]}$ mandibular resection, ${ }^{[5]}$ increase blood loss, ${ }^{[11]}$ flap reconstruction ${ }^{[0-11]}$ were associated with complex and extensive surgeries and were the significant factors leading to increase wound complications. Excision of more advanced tumors leaves extensive defects requiring more complex reconstructions and lead to more errors in surgical technique and judgment. Other studies also had showed the wound infection rate of $20-37 \%$ with flap reconstructions. ${ }^{[5,6]}$ Our results showed that increase blood loss more than $1000 \mathrm{ml}$ leads to significant wound complications. Use of blood replacement is also a statistically significant risk factor for wound complications. ${ }^{[7,10]}$

It is obvious that the clean surgeries will have less complication rate than the clean-contaminated cases. ${ }^{[8]}$ Poor oral hygiene was significant factor associated with wound infections. Pre-operative dental scaling and good oral hygiene are important factors to prevent wound complications.

Low post-operative hemoglobin was the significant predictor of wound complications. The mechanism is not known, but low hemoglobin may represent poor general health, blood loss during surgery or impaired oxygen delivery to surgical wounds leading to poor wound healing. ${ }^{[8]}$

As oppose to other studies, we did not find any correlation of wound complication with respect to advanced age, body mass index and ASA score, pre-operative radiotherapy ${ }^{[8,10]}$ and pre-operative chemotherapy. ${ }^{[2,3]}$

\section{CONCLUSION}

Head and neck cancer surgeries are complex, extensive and are associated with increased risk of wound complications.
Factors such as advanced T stage, tracheostomy, mandibular reconstructions and flap reconstruction are unavoidable and part of the disease management. The current study demonstrates low level of albumin (below $3.7 \mathrm{~g} / \mathrm{dl}$ ) is associated with an increased risk of wound infection. The nutritionist therefore must be an integral part of the multi - disciplinary team and extra effort must be made to maintain post-operative albumin level above $4 \mathrm{~g} / \mathrm{dl}$. Precautionary measures such as maintenance of adequate nutrition and hemoglobin levels may play a critical role in preventing wound complications.

The study also shows that risk of wound infection increases with the increase in operative time. Repeating the antibiotic dose in a prolonged surgery at an appropriate time is a critical step, which is often forgotten.

Apart from this, pre-operatively dental scaling, good oral hygiene and maintenance of operating room asepsis should be done to prevent wound infection.

It is essential to recognize the factors responsible for wound infection and to take appropriate measures perioperatively to minimize the wound complications so as to prevent any delay in the adjuvant treatment and associated added cost to patient and hospital.

\section{ACKNOWLEDGMENT}

The authors would like to thank Ms. Rohini W. Hawaldar, Statistician, Tata Memorial Hospital.

\section{REFERENCES}

1. Parsons JT, Mendenhall WM, Stringer SP, Cassisi NJ, Million RR. An analysis of factors influencing the outcome of postoperative irradiation for squamous cell carcinoma of the oral cavity. Int J Radiat Oncol Biol Phys 1997;39:137-48.

2. Penel N, Lefebvre D, Fournier C, Sarini J, Kara A, Lefebvre JL. Risk factors for wound infection in head and neck cancer surgery: A prospective study. Head Neck 2001;23:447-55.

3. Penel N, Fournier C, Lefebvre D, Lefebvre JL. Multivariate analysis of risk factors for wound infection in head and neck squamous cell carcinoma surgery with opening of mucosa. Study of 260 surgical procedures. Oral Oncol 2005;41:294-303.

4. Penel N, Fournier C, Roussel-Delvallez M, Lefebvre D, Kara A, Mallet $Y$, et al. Prognostic significance of wound infections following major head and neck cancer surgery: An open non-comparative prospective study. Support Care Cancer 2004;12:634-9.

5. Belusic-Gobic M, Car M, Juretic M, Cerovic R, Gobic D, Golubovic V. Risk factors for wound infection after oral cancer surgery. Oral Oncol 2007;43:77-81.

6. Brown BM, Johnson JT, Wagner RL. Etiologic factors in head and neck wound infections. Laryngoscope 1987;97:587-90.

7. Robbins KT, Favrot S, Hanna D, Cole R. Risk of wound infection in patients with head and neck cancer. Head Neck 1990;12:143-8. 
8. Schwartz SR, Yueh B, Maynard C, Daley J, Henderson W, Khuri SF. Predictors of wound complications after laryngectomy: A study of over 2000 patients. Otolaryngol Head Neck Surg 2004;131:61-8.

9. Lotfi CJ, Cavalcanti Rde C, Costa e Silva AM, Latorre Mdo R, Ribeiro Kde C, Carvalho AL, et al. Risk factors for surgicalsite infections in head and neck cancer surgery. Otolaryngol Head Neck Surg 2008;138:74-80.

10. Farwell DG, Reilly DF, Weymuller EA Jr, Greenberg DL, Staiger TO, Futran NA. Predictors of perioperative complications in head and neck patients. Arch Otolaryngol Head Neck Surg 2002;128:505-11.

11. Ogihara $H$, Takeuchi $K$, Majima $Y$. Risk factors of postoperative infection in head and neck surgery. Auris Nasus Larynx 2009;36:457-60.

12. de Luis DA, Aller R, Izaola O, Cuellar L, Terroba MC.
Postsurgery enteral nutrition in head and neck cancer patients. Eur J Clin Nutr 2002;56:1126-9.

13. Fusconi M, Gallo A, Vitiello C, Pagliuca G, Pulice G, de Vincentiis $M$. Clean-contaminated neck surgery: Risk of infection by intrinsic and extrinsic factors. Arch Otolaryngol Head Neck Surg 2006;132:953-7.

14. Coskun H, Erisen L, Basut O. Factors affecting wound infection rates in head and neck surgery. Otolaryngol Head Neck Surg 2000;123:328-33.

How to cite this article: Chaukar DA, Deshmukh AD, Majeed T, Chaturvedi P, Pai P, D'cruz AK. Factors affecting wound complications in head and neck surgery: A prospective study. Indian J Med Paediatr Oncol 2013;34:247-51

Source of Support: Nil, Conflict of Interest: None declared.

Announcement

\section{Android App}

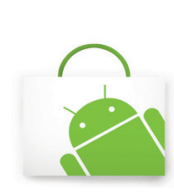

A free application to browse and search the journal's content is now available for Android based mobiles and devices. The application provides "Table of Contents" of the latest issues, which are stored on the device for future offline browsing. Internet connection is required to access the back issues and search facility. The application is compatible with all the versions of Android. The application can be downloaded from https://market.android.com/details?id=comm.app.medknow. For suggestions and comments do write back to us. 